\title{
Redesain Interior Studio Toha Bernuansa Homey dengan Pengaplikasian Teknologi dan Easy Maintenance Material
}

\author{
Mutiara Hanifa dan Aria Weny Anggraita \\ Departemen Arsitektur, Fakultas Teknik Sipil dan Perencanaan, Institut Teknologi Sepuluh Nopember (ITS) \\ e-mail: aria.weny@yahoo.com
}

\begin{abstract}
Abstrak-Stasiun televisi adalah salah satu media informasi dan komunikasi yang digunakan di Indonesia. Salah satu sarana pada stasiun televisi adalah studio televisi. Studio televisi memiliki beberapa fasilitas-fasilitas pendukung didalamnya, seperti ruang make-up, wardrobe, control room, audio control room dan workshop. Fasilitas-fasilitas tersebut digunakan oleh pengguna dengan jangka waktu maksimal 6 × 24 jam. PT. Netmediatama sebagai salah satu stasiun televisi di Indonesia memiliki atau menyewa beberapa studio televisi, salah satunya adalah Studio Toha yang berada di kawasan Bintaro. Dalam meningkatkan produktivitas karyawan PT. Netmediatama, kenyamanan dalam beraktivitas pada studio televisi memiliki andil yang besar. Penerapan teknologi-teknologi yang sesuai dengan karakteristik pengguna juga dapat diaplikasikan untuk hiburan disela-sela aktivitas yang padat. Hal tersebut dapat mencegah pengguna merasakan tekanan akibat overwork. Studio Toha memiliki suasana interior yang cenderung gelap dan suram, materialmaterial yang digunakan membutuhkan maintenance yang merepotkan, dan kurangnya teknologi di dalam interior Studio Toha yang menyesuaikan karakter penggunanya. Oleh karena itu, desain interior homey dan pengaplikasian teknologi diterapkan untuk mengurangi ketegangan suasana didalam Studio Toha. Konsep easy maintenance diterapkan untuk mempermudah pengelola dalam merawat fasilitas yang ada di Studio Toha. Pada penerapannya, karakteristik konsep homey yang diaplikasikan kedalam interior Studio Toha adalah warna hangat pada elemen interior serta peletakkan aksesoris interior seperti tanaman indoor, hiasan dinding, serta peletakan bantal pada sofa, sedangkan penerapan easy maintenance yaitu pada material finishing pada dinding, lantai, plafon dan bentukan furniture. Pengaplikasian Teknologi dalam interior Studio Toha adalah berupa sarana informasi yang menggunakan teknologi terbaru seperti media wall OLED dan pengaplikasian make- up virtual pada transparant mirror media OLED untuk mempermudah aktivitas pengguna di dalamnya. Maka, dengan diterapkannya konsep homey, easy maintenance dan Teknologi, produktivitas kerja pengguna yang ada di dalamnya meningkat karena berkurangnya dampak kepadatan aktivitas yang dilakukan oleh pengguna di dalam Studio Toha.
\end{abstract}

Kata Kunci-Studio Televisi, Studio Toha, Homey, Teknologi, Easy Maintenance Material.

\section{PENDAHULUAN}

$\mathrm{S}_{\mathrm{u}}^{\mathrm{E}}$ EIRING dengan perkembangan jaman, media atau alat untuk informasi dan hiburan tidak lagi tersajikan dalam beSntuk cetak (koran, majalah) ataupun pagelaran seni (secara langsung) melainkan tersedia berupa media elektronik, salah satunya adalah televisi. Kebutuhan masyarakat akan informasi ataupun hiburan semua tersedia di televisi. Tayangan-tayangan yang ditampilkan, mencakup seluruh usia. Anak-anak disuguhi dengan tayangan serial kartun, untuk bapak-bapak yang gemar olahraga tersedia pula tayangan kompetisi olahraga, dan untuk ibu-ibu rumah tangga yang gemar memasak pun diberikan tayangan-tayangan berupa demo memasak.

Di Indonesia terdapat beberapa stasiun televisi yang telah berada pada naungan dan pengawasan dari Komisi Penyiaran Indonesia (KPI), salah satunya adalah PT. Net Mediatama. PT. Net Mediatama atau yang biasa dikenal dengan NET TV adalah bagian dari kelompok usaha INDIKA GROUP yang bergerak di bidang usaha Event Organizer, Promotor, Broadcast Equipment, Production House dan Radio. Sesuai perkembangan teknologi informasi, NET didirikan dengan semangat bahwa konten hiburan dan informasi di masa mendatang akan semakin terhubung, lebih memasyarakat, lebih mendalam, lebih pribadi, dan lebih mudah diakses dimanapun.

Untuk dapat menjangkau visi dan misinya, NET. memiliki atau menyewa beberapa studio yang digunakan untuk melakukan proses produksi, salah satu studio yang disewa oleh PT Net Mediatama adalah Studio Toha yang terletak di Ciputat, Tangerang Selatan. Studio Toha tersebut terdiri dari beberapa set studio untuk proses shooting. Acara-acara pada NET yang proses produksinya berlangsung di Studio Toha adalah Tetangga Masa Gitu, Comedy Night Live dan Waktu Indonesia Bercanda. Proses produksi tersebut melibatkan banyak pihak, mulai dari talent, crew, penonton dan lain-lain.

Dalam memaksimalkan proses produksi pada Studio, dibutuhkan desain interior yang memenuhi kebutuhan serta kenyamanan penggunanya dalam melakukan aktivitas. Pada eksisting Studio Toha bata ekspos digunakan sebagai material pada dinding yang harus di coating setiap 4 bulan sekali, serta plester semen sebagai material pada lantai, sehingga secara keseluruhan suasana yang tercipta pada Studio Toha cenderung gelap dan agak suram. Studio Toha tersebut digunakan oleh NET selama kurang lebih 5-6 hari dalam seminggu, dan dalam waktu 1 hari biasanya digunakan bisa sampai 24 jam, jika dibutuhkan pengerjaan set untuk shooting. Selain itu, kebutuhan akan teknologi yang sesuai dengan karakteristik pengguna, yang mana adalah generasi muda, kurang terpeuhi. Oleh karena itu perlu diadakan redesain interior Studio Toha dengan suasana yang homey dan pengaplikasian teknologi dan material-material yang easy maintenance. 


\section{A. Rumusan Masalah}

1. Bagaimana menerapkan konsep homey pada Studio Toha dan disertai dengan ketentuan-ketentuan Studio Televisi pada umumnya?

2. Bagaimana menerapkan konsep easy maintenance pada Studio Toha?

3. Bagaimana pengaplikasian Teknologi pada Studio Toha?

\section{URAIAN PENELITIAN}

\section{A. Metode Pengumpulan Data}

Metode pengumpulan data melalui studi literatur pengenalan masalah dan informasi yang berhubungan dengan obyek melalui buku referensi ataupun media internet yang dapat menunjang studi riset dan tema desain yang ingin dicapai. Serta proses pengumpulan data dengan cara terjun ke lapangan secara langsung dan melakukan observasi langsung kegiatan yang terjadi pada objek yang diteliti yaitu Studio Toha. Selain itu penulis juga melakukan interview dengan pengurus sekaligus perancang Studio Toha.

\section{B. Metode Analisa Data}

Tahapan desain yang dilakukan oleh penulis setelah melakukan observasi adalah menganalisa hasil observasi dan interview. Setelah tahap analisa hasil observasi dan interview, ditemukan masalah-masalah yang terdapat pada interior objek, yang dalam hal ini adalah Studio Toha. Kemudian masalah tersebut akan di analisa serta dicarikan solusinya dalam bentuk konsep desain.

\section{Metode Desain}

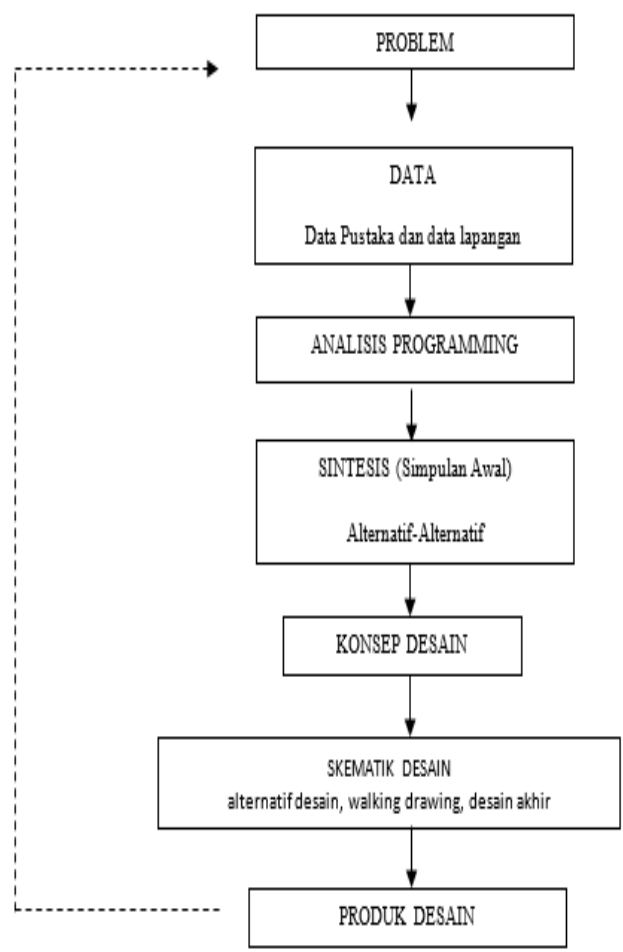

Gambar 1. Alur Metode Desain.

\section{KONSEP DESAIN}

\section{A. Konsep Makro}

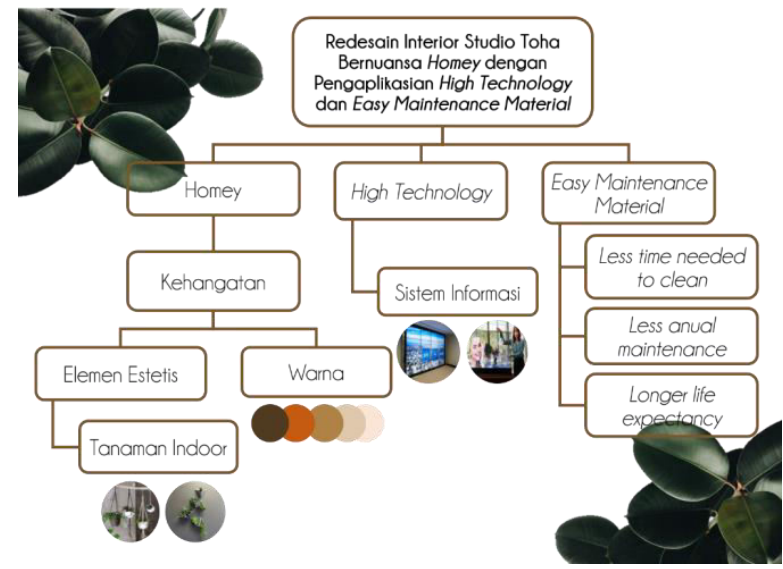

Gambar 2. Rancangan Konsep Desain.

Dalam karakteristik homey, yang akan diambil untuk konsep Studio Toha adalah suasananya. Suasana tersebut dapat terbentuk dengan dukungan material natural, tanaman. Karena homey adalah semua tentang kenyamanan, dan dukungan-dukungan tersebut dianggap dapat mendukung kenyamanan dalam Studio Toha.

Penggunaan material-material dengan karakteristik mudah dibersihkan, memiliki waktu penggunaan jangka lama dan tidak membutuhkan waktu banyak untuk perawatannya. Material-material tersebut akan digunakan sebagai finishing dari elemen-elemen yang ada pada Studio Toha.

Pada konsep Studio Toha, karakteristik Teknologi yang akan diambil adalah warna serta pengaplikasian high technology pada sarana-sarana yang terdapat pada Studio Toha, seperti vitual make-up menggunakan mirror transparant OLED dan media wall OLED.

\section{B. Konsep Mikro}

1) Dinding
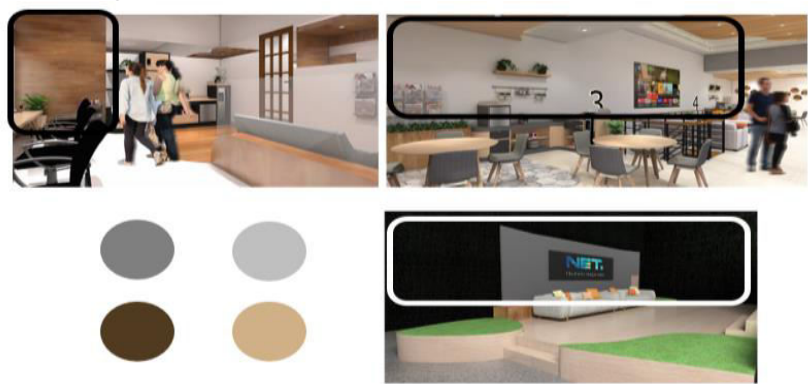

Gambar 3. Desain finishing dinding pada Studio Toha.

Dinding yang diaplikasikan pada interior Studio Toha menggunakan finishing easy to clean cat dinding dan wallpaper vinyl sesuai dengan konsep easy maintenance pada objek. Warna yang digunakan adalah warna netral dan kayu (hangat) untuk menambah kesan homey dalam ruangan.

Sedangkan untuk ruangan-ruangan yang membutuhkan peredam suara, seperti studio, ruang kontrol dan audio control room, finishing dinding yang digunakan adalah acoustic mat. 


\section{2) Lantai}
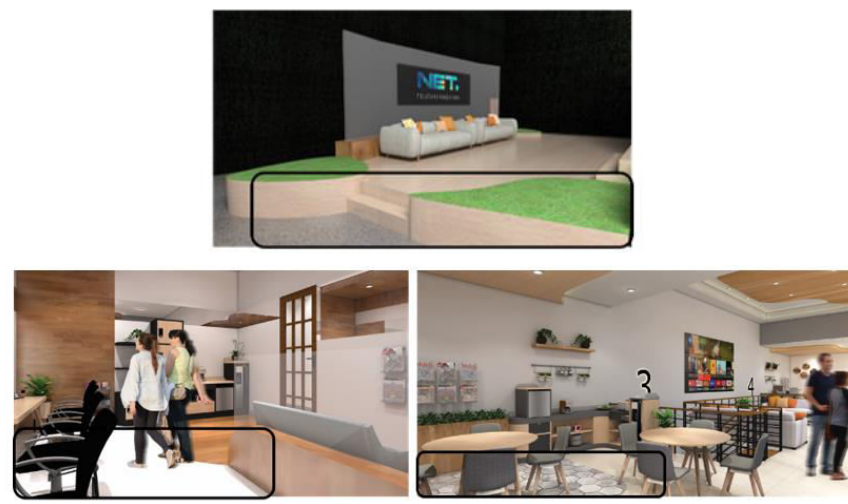

Gambar 4. Desain finishing lantai pada Studio Toha.

Lantai pada Studio Toha memiliki pola dan material yang berbeda-beda. Pada ruang Studio, pola lantai digunakan untuk membatasi sirkulasi antar pengguna (talent, crew, penonton). Alan Berman (1997), mengatakan bahwa vinyl, granit tile dan hexagon tile merupakan material finishing lantai yang mudah untuk dimaintenance. Oleh karena itu, material tersebut akan digunakan pada finishing lantai interior Studio Toha.

\section{3) Konsep Plafon}
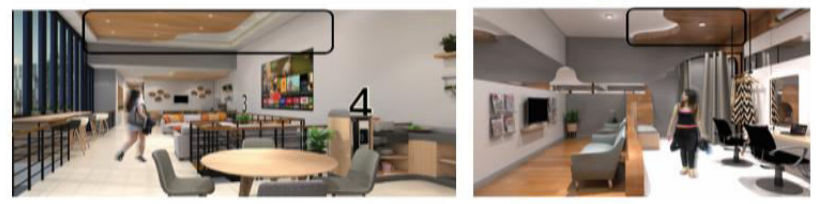

Gambar 5. Desain finishing plafon pada Studio Toha.

Plafon pada area makeup dan istirahat menggunakan plafon kombinasi drop ceiling dengan material pvc. Plafon pvc digunakan karena pvc adalah material yang easy maintenance. Motif yang digunakan untuk plafon adalah motif kayu dan motif polos. Bentukan-bentukan yang digunakan pada drop ceiling adalah bentukan yang menghindari sudut, hal ini dilakukan agar memudahkan proses pembersihan. Selain pada ceiling bentukan-bentukan tersebut juga digunakan untuk lantai.

4) Pencahayaan
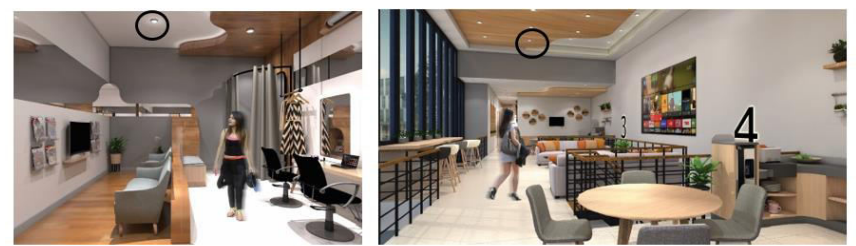

Gambar 6. Penggunaan pencahayaan pada interior Studio Toha.

Pada area makeup, pencahayaan yang digunakan adalah pencahayaan buatan, karena ruang makeup tidak memiliki akses jendela sama sekali. Pada area makeup, pencahayaan yang digunakan lebih terang dibandingkan pada area tunggu. Hal ini disebabkan karena aktivitas yang dilakukan pada area makeup lebih detail.

Area santai memanfaatkan pencahayaan alami secara maksimal, hal tersebut dapat terlihat dari pengaplikasian jendela besar didepan meja bar. Hal tersebut dianggap dapat mengurangi rasa penat yang dialami crew selama beraktivitas di studio saat beristirahat.

Sedangkan untuk jenis lampu yang digunakan pada interior Studio Toha adalah hidden lamp pada drop ceiling dan juga downlight untuk lampu general.

\section{5) Furniture}
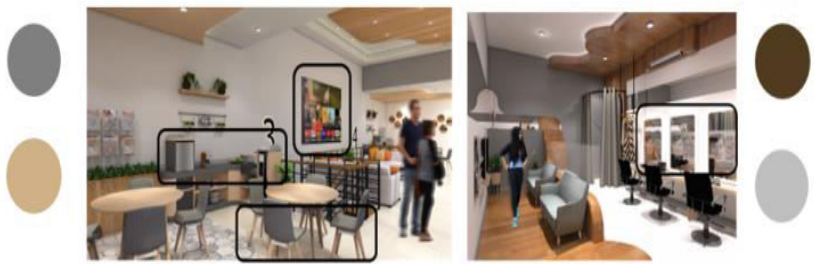

Gambar 7. Penggunaan furniture pada interior Studio Toha.

Bentuk yang digunakan pada furniture Studio Toha adalah bentukan-bentukan yang menghindari sudut sehingga mudah untuk dibersihkan, selain itu juga pengaplikasian furniture dengan mengurangi luas pada alas penampang untuk memudahkan proses pembersihan pada lantai.

Pada interior Studio Toha juga diaplikasikan sarana yang berbasis Teknologi. Dapat dilihat pada gambar disamping terdapat media wall OLED sebagai sarana entertainment dan pada gambar dibawah terdapat cermin yang dilengkapi dengan mirror transparant OLED untuk menghemat waktu dalam proses melakukan makeup.

\section{6) Elemen Estetis}
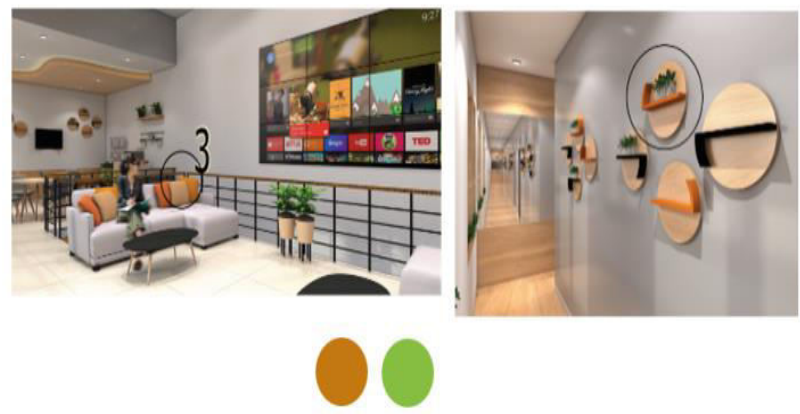

Gambar 8. Penggunaan furniture pada interior Studio Toha.

Untuk elemen estetis yang digunakan pada Studio Toha adalah beruba tanaman hias dan asesoris-asesoris ruangan seperti bantal pada sofa dan hiasan dinding. Warna yang diambil untuk elemen estetis adalah orange. Warna hangat tersebut dipilih untuk menambah kesan homey dalam interior ruangan.

\section{DESAIN AKHIR}

\section{A. Ruang Make-Up Artis Perempuan}

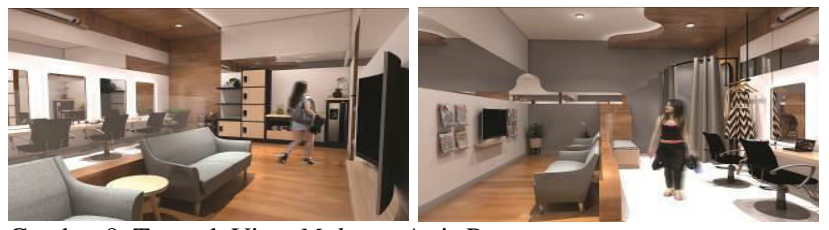

Gambar 9. Tampak View Make-up Artis Perempuan. 
Konsep homey diaplikasikan dalam bentuk warna yang dalam ruang make-up perempuan juga berupa material, yaitu material vinyl dengan motif kayu yang digunakan pada lantai, plafon dan furniture. Selain itu, pada gambar diatas juga terlihat bahwa penerapan easy maintenance berupa bentukanbentukan elemen interior maupun furniture yang menghindari sudut serta pengurangan alas penampang pada beberapa material agar memudahkan proses pembersihan. Dalam ruang make-up perempuan, pengaplikasian Teknologi adalah dalam penggunaan Mirror Media OLED sebagai cermin yang dapat digunakan pula sebagai visual make-up.

\section{B. Studio 4}
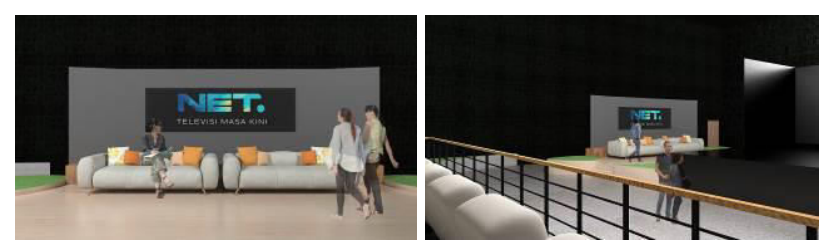

Gambar 10. Tampak View studio 4.

Area menonton untuk artis diletakkan disebelah stage dengan dilengkapi dengan akses tangga untuk naik keatas stage. Di kanan dan kiri area menonton untuk artis juga terdapat elemen estetis berupa rumput-rumput indoor dengan bentuk yang identik, harapannya dapat menambah kehangatan didalam studio 4.

Sedangkan area backstage artis berada di belakang stage. Pada area backstage artis, terdapat media wall OLED yang digunakan untuk memantau waktu standby untuk artis. Didalam area backstage artis juga terdapat tangga akses untuk naik keatas stage.

\section{Area Santai dan Pantry}

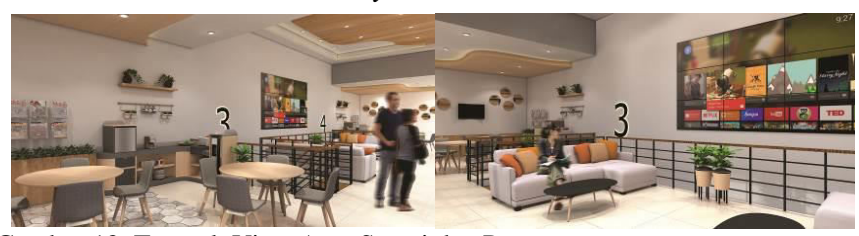

Gambar 12. Tampak View Area Santai dan Pantry.

Area santai difasilitasi oleh sofa dan coffee table. Sofa tersebut dapat digunakan oleh 3-4 orang pada masing-masing sofa. Di sebrang sofa terdapat sebuah minibar yang dapat digunakan juga untuk makan dengan kapasitas 5 orang. Sedangkan pada area pantry terdapat sebuah kitchen set untuk menyiapkan kopi ataupun snack-snack ringan dan fasilitas duduk untuk 8 orang. Pada pantry, tidak disediakan tempat untuk kompor karena didalam studio tidak bahan/alat yang dapat menghidupkan api dilarang untuk memasuki bangunan.

\section{KESIMPULAN}

Pada studio televisi, desain interior mengambil peran penting dalam meningkatkan produktivitas pengguna didalamnya. Sebab pekerjaan yang dilakukan didalam studio televisi adalah pekerjaan dibawah tekanan, hal ini mengakibatkan kebutuhan suasana interior yang dapat meredam tekanan tersebut. Nuansa homey diterapkan untuk mengurangi perasaan kerja dibawah tekanan dengan cara menggunakan warna-warna hangat dan pengaplikasian material dengan motif kayu. Hal ini dapat menguntungkan untuk pihak pengguna maupun perusahaan, karena produktivitas kerja crew juga akan meningkat. Penggunaan konsep easy maintenance material diaplikasikan dalam jenis material dan pengulangan bentuk yang menghindari sudut sehingga dapat memudahkan pengelola bangunan untuk menjaga kebersihan serta keamanan bangunan dan Teknologi yang diterapkan pada sistem informasi dan sarana entertainment dalam bentuk mirror transparant OLED dan media wall OLED dapat meningkatkan kinerja pengguna Studio Toha.

\section{DAFTAR PUSTAKA}

[1] Berman, Alan. 1997. The Complete Book of Floors.

[2] Perbedaan Gypsum dan Kalsiboard., [daring] diakses dari http://www.jasasipil.com/2015/10/perbedaan-plafon-gypsum-dankalsiboard.html_pada tanggal 2 Jananuari 2017

[3] Plavon PVC, [daring] diakses dari http://arafuru.com/properti/ini-diakelebihan-dan-kekurangan-plafon-pvc.html pada tanggal 3 Januari 2017

[4] Dulux Washable \& Tough, [daring] diakses dari http://dulux.com pada tanggal 5 Januari 2017

[5] Jenis Wallpaper, [daring] diakses dari http://wallpaperdindingmurah.weebly.com/ pada tanggal 5 Januari 2017

[6] Axon90. 2016. BRI Digital T3 Soekarno-Hatta. 